\title{
Differential Effect of Isooctane Doses on HaCaT and HeLa: A Multimodal Analysis
}

\author{
Lopamudra Das, ${ }^{1}$ Sanmitra Basu, ${ }^{2}$ Sanghamitra Sengupta, ${ }^{2}$ \\ Soumen Das, ${ }^{1}$ and Jyotirmoy Chatterjee ${ }^{1}$ \\ ${ }^{1}$ School of Medical Science and Technology, Indian Institute of Technology Kharagpur, Kharagpur 721302, India \\ ${ }^{2}$ Department of Biochemistry, Ballygunge Science College, University of Calcutta, 35 Ballygunge Circular Road, Kolkata 700019, India
}

Correspondence should be addressed to Lopamudra Das; lopamudra.das.iitkgp@gmail.com

Received 4 July 2014; Accepted 10 September 2014; Published 9 October 2014

Academic Editor: Sung Y. Eum

Copyright (C) 2014 Lopamudra Das et al. This is an open access article distributed under the Creative Commons Attribution License, which permits unrestricted use, distribution, and reproduction in any medium, provided the original work is properly cited.

A multimodal approach is effective in analyzing biological problems critically and thus also useful in assessing cytotoxicity under chemicals assaults. In this study effects of isooctane, an organic solvent and component of gasoline produced in petroleum industries, have been explored on normal (HaCaT) and cancerous (HeLa) epithelial cells. Besides morphological alterations, impacts on viability, prime molecular expressions, and bioelectrical properties on exposure to different doses of isooctane were noted. Scanning electron microscopy and viability assay demonstrated remarkable structural alterations and cell death, respectively, in $\mathrm{HaCaT}$ but not in HeLa. Transcriptomic and immunocytochemical studies on E-cadherin expression also elucidated pronounced toxic effects on HaCaT. Remarkable changes on the bioelectrical properties (e.g., impedance and phase angle) of the HaCaT, in contrast to $\mathrm{HeLa}$, at different temporal points on isooctane exposure also indicated cytotoxic effects in the former. Hence this study illustrated cytotoxicity of isooctane on HaCaT multidimensionally which was evaded by HeLa.

\section{Introduction}

Profuse use of chemicals in modern times is posing serious threats to the health and environment. The number of synthetic substances to which humans are exposed has increased enormously over the last decades as well [1]. In the context of hazards, toxic effect of organic solvents (OS) is a major health concern [2] especially due to their cytotoxicity [3] and protein denaturing effects $[3,4]$. Isooctane $(\mathrm{IO})$ is one of such synthetic OS and needs better attention particularly to elucidate its impact on mammalian objects [5]. It is produced on a massive scale in the petroleum industry by distillation of petroleum [6] and is an important component of gasoline. IO is useful for production of ethanol with extremely low volatility [7]. Structurally it has high octane number and does not contain any aromatics, metals, or sulphur. In 2008 the worldwide market of IO was expected to be 1.0 million tons approximately [8].

The toxicity of any OS depends on the cell type and its physiological state [9]. The primary site of cytotoxic action is cytoplasmic membrane of cells [3]. Cytotoxicity of IO on microorganism like yeast has already been reported [10] but its impact on the mammalian cells is not well documented. Only the positive effect of IO in combination with acetic acid in psoriasis is reported [11]. The epithelium is the interface between body and external environment. Its tightly packed cells (namely, keratinocytes) are effective barriers between the underlying tissues and involved in diverse functions $[12,13]$ and obviously varied epithelium is exposed to physical and chemical assaults more frequently than any other tissues [14]. Nevertheless, $90 \%$ cancers originate from epithelial cells [15]. So, better understanding of IO's effects on normal and malignant cells of epithelial origin, namely, HaCaT (normal keratinocyte) and HeLa (cancerous keratinocyte), respectively, may be meaningful from multiple aspects.

The evaluation of IO cytotoxicity could be performed from varied dimensions especially to reveal its effects on structural and functional integrity of cells [16]. In such studies correlated assessment of changes in the cellular viability and ultrastructure, molecular expressions including bioelectrical properties are gaining importance [17]. The cell viability assay renders useful information on the cytotoxic effect of 
a chemical and data may be correlated with the OS toxicity [18]. The cells under assaults become stressed, resulting in an altered functioning having impacts on morphological features and cell-cell association [19]. In the context of cellular association, expression of E-cadherin by keratinocyte in confluence is important for formation of adherent junction that leads to compact epithelial architecture [20]. The change in the membranous expression of E-cadherin brings jeopardy in epithelial integrity [21].

Further the studies on bioelectrical properties of cells and their alterations under assaults [22] may be important in the evaluation of cytotoxicity under chemical assault [23]. A cell is electrically neutral but generates electromotive force (EMF) to maintain potential difference and uses varying resistance, impedance, and capacitance [24] in modulating flow of current [25]. In different functional as well as in adhered conditions, cells exhibit changes in membrane potential, impedance, charge distribution, and so forth $[26,27]$. Thus, investigation of cellular electrical behavior when subjected to an electric field may be useful to understand the alteration in cellular function under assault. Monitoring passive electrical properties of biological cells in suspension can yield a lot of information regarding cellular structure and physiology [28], death, and toxicity [29]. In general, label free dielectric spectroscopic measurement on cell suspension is somewhat simple, noninvasive, and real time technique. It provides crucial information about cell proliferation, morphology, and motility.

Several research workers $[27,30,31]$ revealed an increase in impedance with the formation of epithelial sheet due to cell-cell adhesion, proliferation, and spreading. Chakraborty et al. [31] and Heijink et al. [22] reported the effect of Ecadherin regulation by monitoring the real time changes in the epithelial resistance using ECIS. The spreading and attachment of the epithelial cells transfected with siRNA were monitored for $72 \mathrm{hrs}$ in ECIS device by assessing the resistance at a low frequency (i.e., $400 \mathrm{~Hz}$ ) and also the capacitance at a high frequency (i.e., $40 \mathrm{KHz}$ ). A decrease in capacitance value was observed in the first phase after seeding of the cells. However, resistance of the system increased in the later phase which reflected the establishment of tight cell-cell adhesion in the confluent monolayer where current flow between neighboring cells was restricted. Cells transfected with siRNA showed less pronounced increase in resistance due to downregulation of E-cadherin resulting in reduction in the formation of intercellular junctions [22].

In this study, to assess cellular electrical properties under IO exposures, cell based biosensors (cytosensors) were employed. They are hybrid systems and utilize live cells as sensing elements to monitor physiological changes induced by internal aberration or external stimuli [32]. Cytosensors are commonly used for impedance characterization since it can be applied without labeling. Impedance cytosensors offer instantaneous and quantitative means to monitor cellular events, such as changes of ionic channels as well as membrane integrity, cell spreading, motility, and growth [33, 34], and to detect analytes by converting cellular responses into a measurable electrical signal $[26,35]$. Impedance cytosensors have been employed to detect both toxic and noxious agents
[36-38] and to monitor apoptosis induced changes in cell shape [39-41].

In this paper the effect of different doses of isooctane was studied on HaCaT and HeLa cell lines to record the changes in their structure, viability, and prime molecular expression along with electrical impedance under the influence of an electric field on ECIS specialized slides. Attempts have been made to correlate the electrical properties with their molecular expressions, viability, and ultrastructural change after IO exposure.

\section{Materials and Methods}

2.1. Materials. HaCaT and HeLa cells were obtained from NCCS (Pune, India). Fetal bovine serum (FBS), DMEM-F12, MEM, antimycotic antibiotic, L-glutamine, and $0.05 \%$ trypsin-EDTA solution, phosphate buffered saline (PBS), HiPure kit were collected from Himedia (India). Isooctane was from Merck (Germany), Live-dead cell assay kit was from Invitrogen (Frederick, MD), High-Capacity cDNA Reverse Transcription Kit (Applied Biosystems, USA), iQ Sybr Green Supermix (BioRad, CA, USA), goat serum, E-cadherin, and Goat polyclonal to rabbit IgG (Abcam, UK), DAPI (SigmaAldrich, USA).

2.2. Cell Culture and Treatment. HaCaT and HeLa cells were seeded in concentration of $10^{5}$ cells/mL in DMEM F12 and MEM medium, respectively, supplemented with $10 \%$ FBS, $1 \%$ $\mathrm{L}$-glutamine, and $1 \%$ antibiotics. Cells were cultured in $25 \mathrm{~cm}^{2}$ culture flasks in a humidified incubator at $37^{\circ} \mathrm{C}$ with $5 \% \mathrm{CO}_{2}$ [42]. HaCaT cells were cultured for 4 days and HeLa cells were cultured for 2 days to achieve confluent $\left(\sim 10^{6}\right.$ cells $\left./ \mathrm{mL}\right)$ population [43]. The confluent populations of $\mathrm{HaCaT}$ and $\mathrm{HeLa}$ were incubated for $5 \mathrm{hrs}$ with respective media $(2000 \mu \mathrm{L}$ as the final volume) containing $4 \%(80 \mu \mathrm{L}), 6 \%(120 \mu \mathrm{L})$, and $8 \%$ $(160 \mu \mathrm{L})$ of IO and subsequently the effects were studied multimodally. Cells without IO exposure served as control [43].

2.3. Phase Contrast Microscopy (PCM). The PCM of both control and experimental (treated with IO doses) groups of $\mathrm{HaCaT}$ and HeLa cell lines were performed. The digital images ( $1388 \times 1040$ pixels) were taken by CCD camera (AxioCam MRm) in phase contrast mode of Zeiss Observer microscope (model Z1, Carl Zeiss, Germany), under 40x objective [numerical aperture (NA) 0.55 with $0.16 \mu \mathrm{m}$ resolution].

2.4. Live-Dead Cell Assay. Live-dead cell assay was performed using Invitrogen kit on both cell lines after IO treatment at different doses. The digital images were grabbed by CCD camera in ApoTome mode with Zeiss Observer microscope using metal halide light source and green filter for FITC and red filter for Texas Red under 20x objectives (NA 0.8 and $0.31 \mu \mathrm{m}$ resolutions).

2.4.1. Counting Live and Dead Cells. Image frames of livedead cell assay were used for quantification of cell viability. The cells were counted at 10 different locations of each image 
TABLE 1: Conditions for RT.

\begin{tabular}{lcccc}
\hline Step & Step 1 & Step 2 & Step 3 & Step 4 \\
\hline Temperature $\left({ }^{\circ} \mathrm{C}\right)$ & 25 & 37 & 85 & 4 \\
\hline Time (Minute) & 10 & 120 & 5 & $\infty$ \\
\hline
\end{tabular}

TABle 2: Primer sequences and cycling conditions for real time PCR.

\begin{tabular}{|c|c|c|}
\hline Genes & Expression primers and cycling conditions & Product size \\
\hline 18s rRNA & $\begin{array}{l}\text { FP: GTAACCCGTTGAACCCCATT } \\
\text { RP: CCATCCAATCGGTAGTAGCG } \\
\text { Cycling: } 95^{\circ} \mathrm{C} \text { for } 5 \text { minutes ( } 1 \text { cycle), } 95^{\circ} \mathrm{C} \text { for } 30 \mathrm{sec}, 55^{\circ} \mathrm{C} \text { for } 30 \mathrm{sec}, 72^{\circ} \mathrm{C} \text { for } 30 \mathrm{sec}(40 \mathrm{cycles})\end{array}$ & $151 \mathrm{bp}$ \\
\hline E-cadherin & $\begin{array}{l}\text { FP: CGGGAATGCAGTTGAGGATC } \\
\text { RP: AGGATGGTGTAAGCGATGGC } \\
\text { Cycling: } 95^{\circ} \mathrm{C} \text { for } 5 \text { minutes ( } 1 \text { cycle), } 95^{\circ} \mathrm{C} \text { for } 30 \mathrm{sec}, 55^{\circ} \mathrm{C} \text { for } 30 \mathrm{sec}, 72^{\circ} \mathrm{C} \text { for } 30 \mathrm{sec}(40 \mathrm{cycles})\end{array}$ & $201 \mathrm{bp}$ \\
\hline
\end{tabular}

FP: forward primer; RP: reverse primer; bp: base pair.

frame, randomly selected for each sample, and then averaging the counts.

2.5. SEM Characterization. The SEM analysis was carried out by ZEISS EVO 60 Scanning Electron Microscope with Oxford EDS Detector at $20 \mathrm{kV}$ and $9.00 \mathrm{~mm}$ WD. The SEM characterization of $\mathrm{HaCaT}$ and $\mathrm{HeLa}$ was conducted after treatment with different doses of IO.

\subsection{Quantitative Evaluation of Gene Expression through RT-PCR}

2.6.1. Preparation of Cells. The confluent $\mathrm{HaCaT}$ and HeLa cells, $5 \mathrm{hrs}$ after exposure to different doses of IO $(4 \%, 6 \%$, and $8 \%)$, and control were trypsinized and centrifuged at $5000 \mathrm{rpm}$ for $5 \mathrm{~min}$ to prepare the cellular pellet which was further used for RNA isolation. The same method was followed to prepare the samples for bioimpedance study.

2.6.2. RNA Isolation and cDNA Conversion. Extraction of total RNA from cells (control and experimental) with $10^{5}$ cells/mL concentration was done using HiPure kit (HiMedia, India), following the instructions of manufacturer. The quantity and quality of the extracted RNA was checked with spectrophotometer at 260 and $280 \mathrm{~nm}$ and by agarose gel electrophoresis. Reverse transcription reaction was performed using $1 \mu \mathrm{g}$ of RNA with high-capacity cDNA Reverse Transcription Kit (Applied Biosystems, USA) in a GeneAmp PCR System 2720 Thermal Cycler (Applied Biosystems, USA) according to the manufacturer's protocol. Cycling conditions of RT-PCR and sequence primers, annealing, and detection temperature are mentioned in Tables 1 and 2, respectively [44].

2.6.3. Real Time PCR Studies. Real Time PCR reactions for Ecadherin gene were performed in Biorad iCycler instrument (BioRad, CA, USA), using iQ Sybr Green Supermix (BioRad, CA, USA) and $1 \mu \mathrm{L}$ of the $10 \mathrm{X}$ diluted cDNA template in a total reaction volume of $10 \mu \mathrm{L}$. 18s rRNA gene was regarded as an endogenous control. The RT reactions for each sample were done in duplicate to ensure best reproducibility. Negative controls without template were included in each set of PCR assays [44].

The gene expression analysis was based upon the relative quantification method in which the change in mRNA level of a gene was relative to the levels of an internal control RNA (i.e., 18s rRNA). This reference gene was an endogenous control and coamplified in the same PCR condition. For the analysis of E-cadherin expression in the studied cell lines on exposure to IO doses $(4 \%, 6 \%$, and $8 \%$ ) for $5 \mathrm{hrs}$, the control was used as a reference, while the former as target. The $\mathrm{Ct}$ (cycle threshold) value obtained for a gene was normalized using the $\mathrm{Ct}$ value for the endogenous control 18s rRNA yielding $\Delta \mathrm{Ct}$ and the data was plotted for different IO doses.

2.7. Immunocytochemistry for E-Cadherin Expression. The $\mathrm{HaCaT}$ and HeLa cells were fixed with acetone/methanol $(1: 1)$ and in $4 \%$ paraformaldehyde in PBS ( $\mathrm{pH} 7.4)$ solution, respectively, for $10 \mathrm{~min}$ at $25^{\circ} \mathrm{C}$. Thereafter, samples were incubated with $10 \%$ goat serum (ab7481, Abcam, UK) in PBST for $30 \mathrm{~min}$ to block nonspecific binding of the antibodies. The primary antibody for E-cadherin (clone EP700Y, Cat. Number ab40772, Abcam, Cambridge, UK) was diluted to 1:500 in PBS with $1 \%$ bovine serum albumin and incubated for $60 \mathrm{~min}$ at $25^{\circ} \mathrm{C}$. After three washing steps with PBS, cells were incubated with FITC conjugated secondary antibody (Goat polyclonal to rabbit IgG, Cat. Number ab6717, Abcam, Cambridge, UK; $1: 500$ in PBS) for $1 \mathrm{hrs}$ at $25^{\circ} \mathrm{C}$ in dark. Finally, cells were rinsed with PBS and counter stained with DAPI (Sigma-Aldrich, USA). The digital images were grabbed by CCD camera in Apotome mode under Zeiss Observer. Z1 microscope uses metal halide light source and green filter for FITC and blue filter for DAPI under 20x objectives (NA 0.8 and $0.31 \mu \mathrm{m}$ resolutions).

2.7.1. Semiquantification of E-Cadherin Expression. The expression of E-cadherin was semiquantitatively evaluated by computing the grey scale intensity values of the membrane and cytoplasm from ICC images by using Axiovision software (version 4.7.2, Carl Zeiss, Germany). Box plots were 


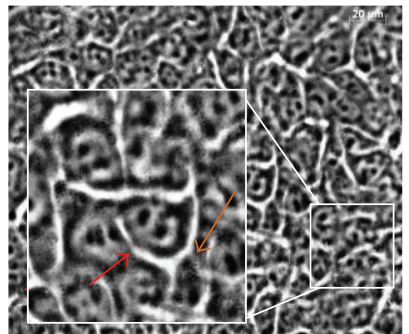

(a)

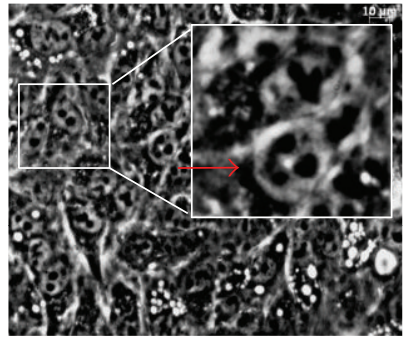

(a1)

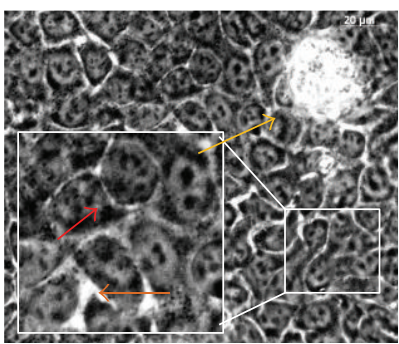

(b)

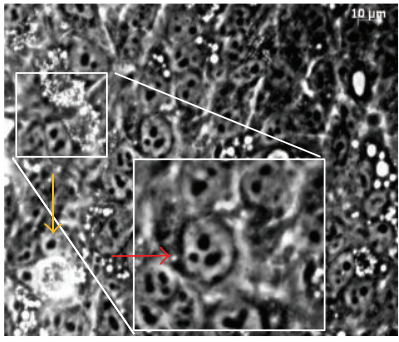

(b1)

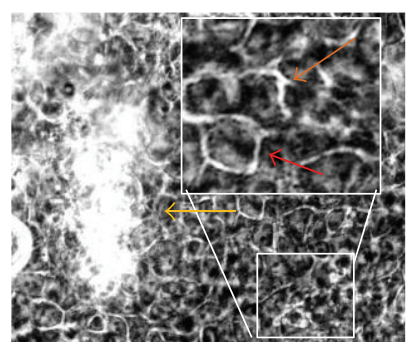

(c)

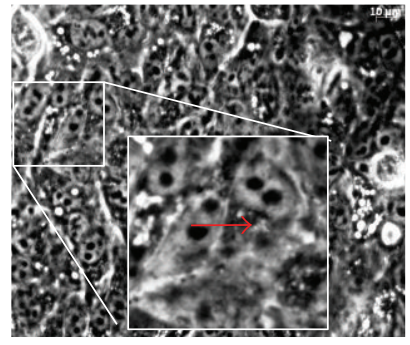

(c1)

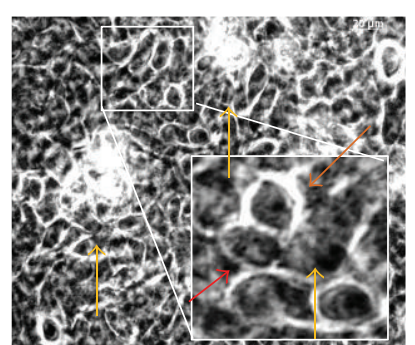

(d)

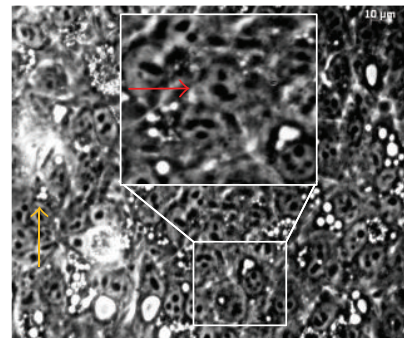

(d1)

FIgURE 1: Phase contrast microscopic images under 40x objective of HaCaT (a-d) and HeLa (al-d1) cells, respectively, of control and 5 hrs after exposure to IO doses. In case of HaCaT, in comparison to control (a) and 4\% IO (b) groups, 6\% (c) and $8 \%$ (d) IO groups depicted drastic changes in the dead cell population with increase in intercellular space as seen in the magnified portion. Phase contrast microscopic images under 40x objectives (al-d1) of HeLa cell of control and after 5 hrs exposure to different IO doses. In comparison to control (a1), no remarkable changes can be observed in the experimental groups (b1-d1) (cell death: yellow arrow); (cell size: red arrow); (intracellular spaces: orange arrow).

constructed using SPSS V.7.5 to compare the variation in E-cadherin immunoexpression.

2.8. Electrical Characterization. Both HaCaT and HeLa cells at a concentration of $10^{4}$ cells $/ \mathrm{mL}$ were seeded in the commercially available ECIS (Electric Cell-substrate Impedance Sensing) slide (model number 8W1E) from Applied Biophysics, USA, and incubated overnight at $37^{\circ} \mathrm{C}$ and $5 \% \mathrm{CO}_{2}$ for subsequent IO exposures and bioelectrical characterization. The cells were then treated with IO at different doses and incubated for $5 \mathrm{hrs}$. The electrical parameters, namely, impedance $(Z)$, and phase angle $(\theta)$, over the frequency range of $100 \mathrm{~Hz}$ to $1 \mathrm{MHz}$ were measured with LCR meter (Hoiki, Japan). ECIS slides were interfaced with the LCR meter. The electrical parameters were recorded just after IO exposure with different doses and also after 5 hrs of intervention. The values of $Z$ and $\theta$ versus frequency were plotted by using Origin8 software.

\subsection{Data Analysis}

2.9.1. Bar Diagram for Cell Viability. The bar diagram for cell viability was prepared by calculating the number of live and dead cells per unit area of $347 \times 260$ pixels.

2.9.2. Box Plot. The box plot was computed from the grey scale intensity value of E-cadherin intensity from ICC images of both $\mathrm{HaCaT}$ and HeLa after IO exposures. For each sample, grey scale intensity values were noted randomly selecting 50 points each for membranous as well as cytoplasmic Ecadherin expression. Box plot for both cell types was computed using SPSS 7.5 software.

2.9.3. Analysis of E-Cadherin RT-PCR Data. Bar diagram was plotted for studying modulation in mRNA expression level in terms of $\Delta \mathrm{Ct}$ for expression of E-cadherin in $\mathrm{HaCaT}$ and HeLa under exposures to IO doses for $5 \mathrm{hrs}$. The level of significance for the differential expression of E-cadherin in HaCaT and HeLa was assessed by Mann-Whitney test using SPSS 7.5.

\section{Results}

3.1. Phase Contrast Microscopy. The PCM microphotographs are shown in Figures 1(a)-1(d) for HaCaT and Figures 1(a1)1(d1) for HeLa of control and experimental groups. Figures 1(a) and 1(a1) exhibited confluent population of HaCaT and $\mathrm{HeLa}$ in respective control groups. The confluent characteristics of $\mathrm{HaCaT}$ were remarkably affected with increase in $\mathrm{IO}$ doses. The effects were very pronounced under $6 \%$ and at $8 \%$ IO doses where clumps of dead cells along with reduction in live cells were visible (Figures 1(b)-1(d)). But HeLa did not show any remarkable change in their confluent characteristics under IO doses (Figures 1(a1)-1(d1)).

3.2. Live-Dead Cell Assay. The PCM observation was further confirmed by "live-dead" cell assay for HaCaT (Figures 2(a)2(d)) and HeLa (Figures 2(a1)-2(d1)) for both control and experimental groups after $5 \mathrm{hrs}$ of treatment. 


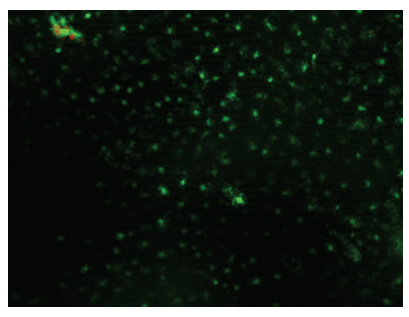

(a)

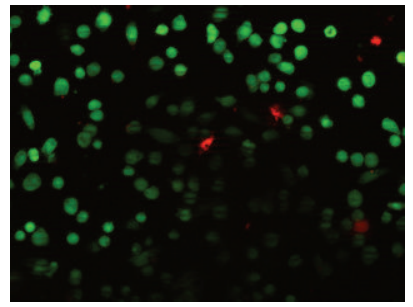

(a1)

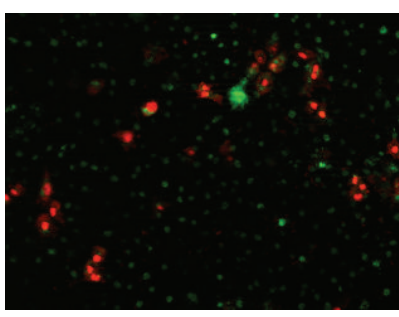

(b)

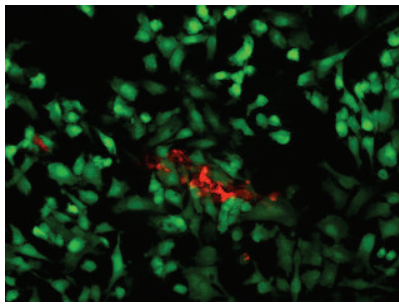

(b1)

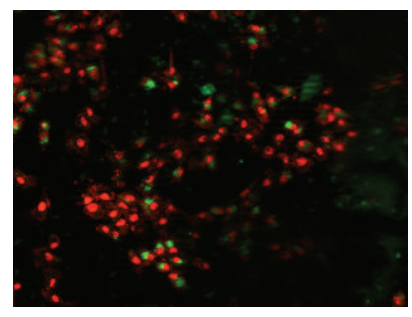

(c)

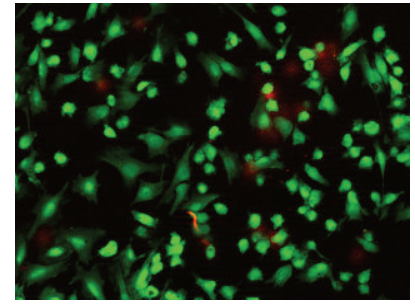

(c1)

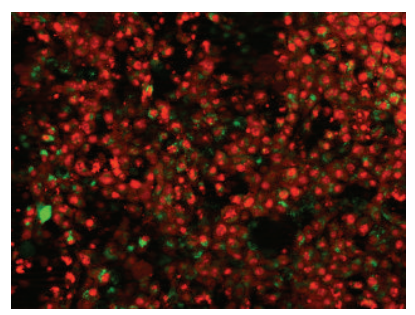

(d)

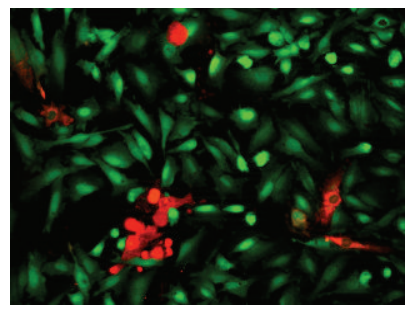

(d1)

Figure 2: Apotome images (20x) of $\mathrm{HaCaT}(\mathrm{a}-\mathrm{d})$ and $\mathrm{HeLa}(\mathrm{al}-\mathrm{dl})$ in control and on exposure to IO at different doses (4\%, 6\%, and $8 \%)$ for 5 hrs. The cells were grown on lysine coated cover slips. Red and green colours indicated dead cells and live cells, respectively.

Green colour represented live cells while dead cells were red. In both control study group (Figures 2(a) and 2(a1)) all cells were green. In $\mathrm{HaCaT}$, with the increment in IO doses, cell death increased remarkably (Figures 2(b) to 2(d)). However, in HeLa, there was no increase in dead cells under increase of IO doses (Figures 2(a1) to 2(d1)).

The comparative viability of $\mathrm{HaCaT}$ and HeLa under different IO doses was computed in form of bar chart (Figure 3) which clearly pointed the constant viability of HeLa even after exposure to $8 \%$ IO by evasion of its toxic effects while a steady fall in cell viability in $\mathrm{HaCaT}$ to nearly $5 \%$ occurred through the increment of IO doses.

3.3. SEM Characterization. Ultrastructural studies depicted a sharp change in cellular morphology and intercellular connectivity as well as surface roughness being reduced in case of $\mathrm{HaCaT}$ (Figures 4(a)-4(d)) in contrast to HeLa (Figures $4(\mathrm{al})-4(\mathrm{~d} 1))$ where no remarkable change was noted under same IO exposures.

\subsection{Quantitative Evaluation of E-Cadherin Expression through} $R T-P C R$. The RT-PCR studies indicated differential impact of IO doses on the expression of E-cadherin in HaCaT and HeLa as shown in Figure $5(P<0.0001)$ after 5 hrs of exposure. In case of $\mathrm{HaCaT}$ there was a downregulation in the said gene in comparison to control and the effect was remarkable especially in higher doses, that is, $6 \%$ and $8 \%$. In case of $\mathrm{HeLa}$ there was no variation in the E-cadherin expression as noted under such IO exposures.

3.5. Immunocytochemistry for E-Cadherin Expression. The ICC observations demonstrated remarkable changes in expression of E-cadherin in HaCaT (Figures 6(a)-6(d)) but

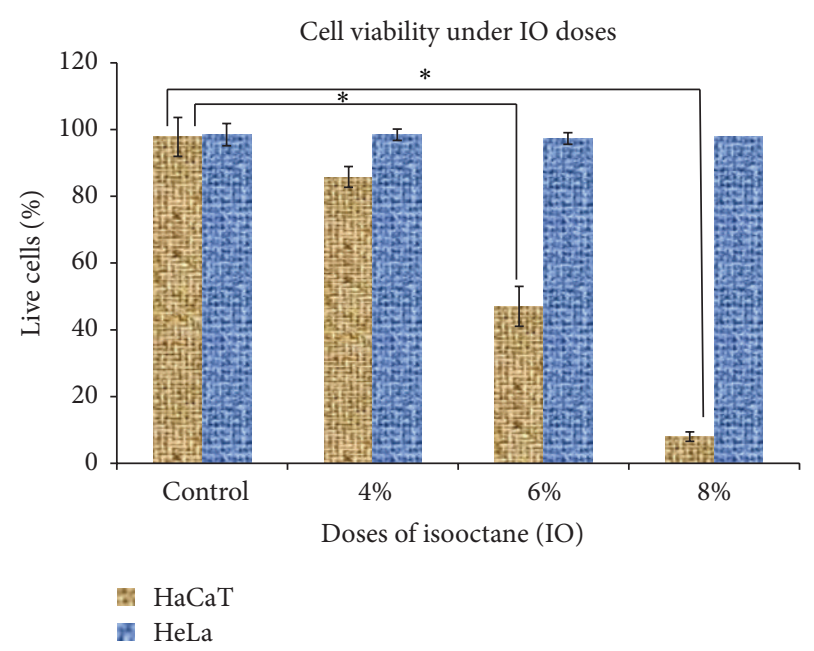

FIGURE 3: Bar chart showing the viability of $\mathrm{HaCaT}$ and HeLa under different doses of IO. $*$ indicates that the data are statistically significant and ${ }^{*} P<0.001$.

not in HeLa (Figures 6(a1)-6(d1)) on incubation with different doses of IO for $5 \mathrm{hrs}$. In case of HaCaT, a loss of membranous E-cadherin expression was noted with concomitant increase in cytoplasmic site on exposure to IO doses and a complete membranous disruption of this molecule was noted at $8 \%$ (Figures $6(\mathrm{a})-6(\mathrm{~d})$ ). But no such changes could be noted in case of HeLa even on exposure to higher IO doses namely $6 \%$ and $8 \%$.

3.5.1. Semiquantification of E-Cadherin Expression. The membranous and cytoplasmic E-cadherin intensity for both cell lines were semiquantified from the ICC images. The box plots for HaCaT (Figure 7(a)) and HeLa (Figure 7(b)) cells with various IO doses were plotted. Here, it was 


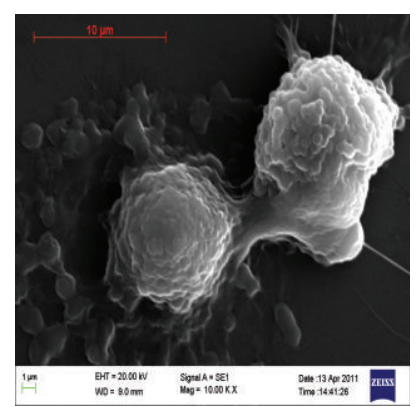

(a)

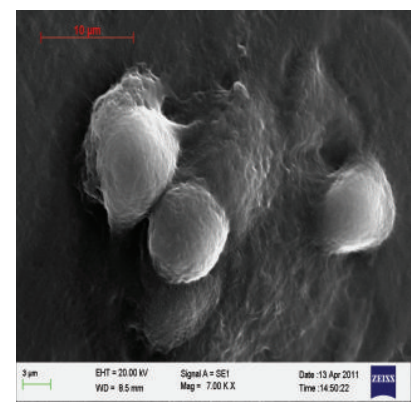

(a1)

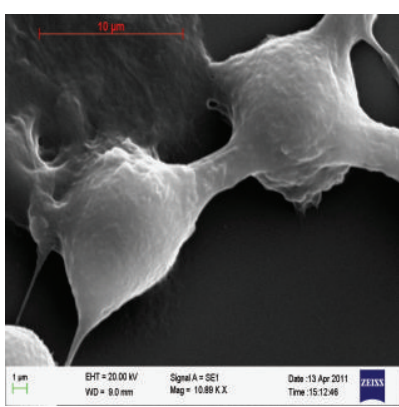

(b)

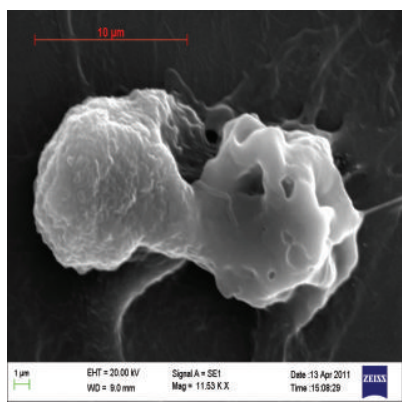

(b1)

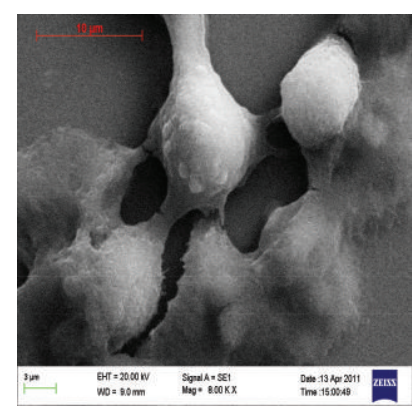

(c)

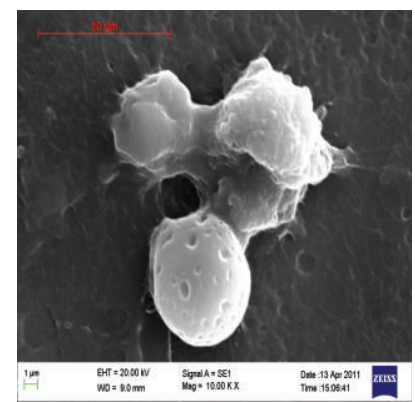

(c1)

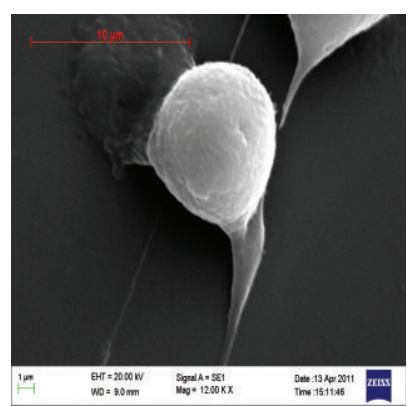

(d)

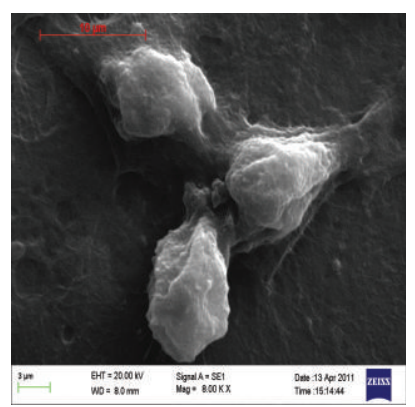

(d1)

Figure 4: SEM images of HaCaT (a-d) and HeLa (al-d1) of control and on exposure to IO at different doses (i.e., $4 \%, 6 \%$, and $8 \%$ ) for 5 hrs. Operating voltage: $20 \mathrm{KV}$ and working distance $=9.00 \mathrm{~mm}$.

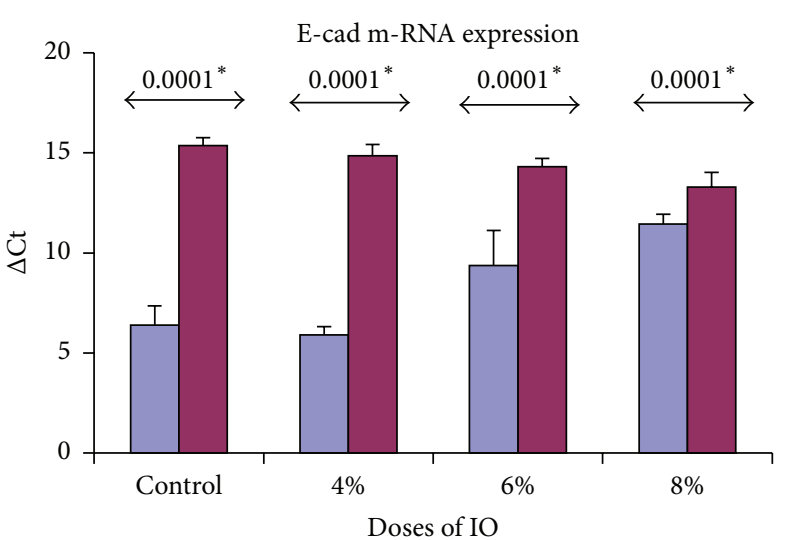

$\square$ HaCaT_ $\Delta \mathrm{Ct}$

$\square$ HeLa_ $\Delta \mathrm{Ct}$

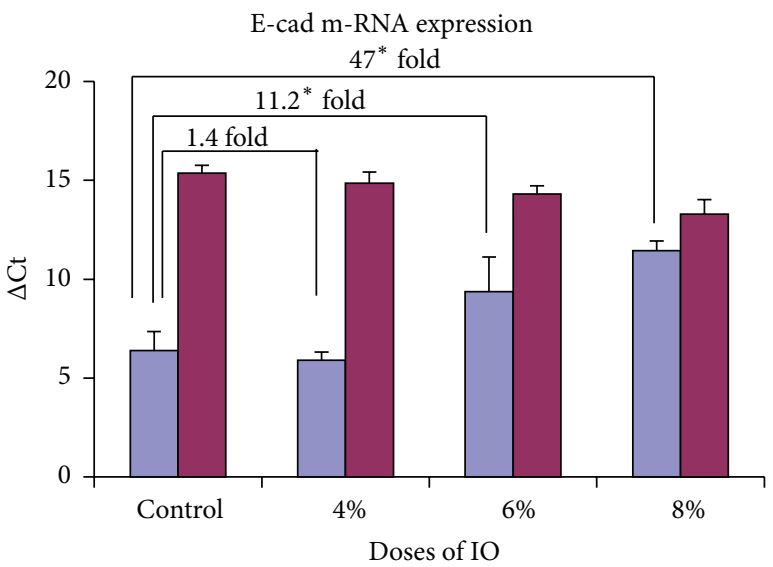

$\square$ HaCaT_ $\Delta$ Ct

$\square$ HeLa_ $\Delta \mathrm{Ct}$

(a)

(b)

Figure 5: Modulation in E-cadherin m-RNA expression in terms of $\Delta \mathrm{Ct}$ in HaCaT and HeLa under chemical assaults with varied doses of IO for 5 hrs. Comparison of E-cadherin expression of HaCaT and HeLa on exposure to different doses of IO. Bar graphs represent $\Delta \mathrm{Ct}$ values of E-cadherin expression with respect to that of 18s rRNA in HaCaT and HeLa under different IO doses after 5 hrs of exposures. * indicates the differences that are statistically significant $(P<0.05)$.

observed that, in case of HaCaT (Figure 7(a)), membranous E-cadherin intensity was decreased progressively with an increase in the cytoplamic E-cadherin concentration under higher doses of IO. But no remarkable changes were noted in HeLa (Figure 7(b)) under such interventions.

3.6. Electrical Impedence Measurement. In the ECIS method, the frequency response of impedance magnitude and phase angle were obtained for $\mathrm{HaCaT}$ and HeLa cells treated with various doses of IO. The magnitude of the frequency response of impedance and phase angle (Figures $8(\mathrm{a})-8(\mathrm{~d})$ ) for $\mathrm{HaCaT}$ and HeLa was computed just after IO exposures and also $5 \mathrm{hrs}$ after such intervention.

From Figure 8(a), it might be observed that the initial value and magnitude of impedance variation were nearly the same for control and up to $6 \% \mathrm{IO}$ treated $\mathrm{HaCaT}$ cells. The 


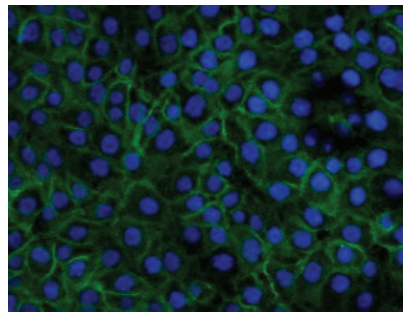

(a)

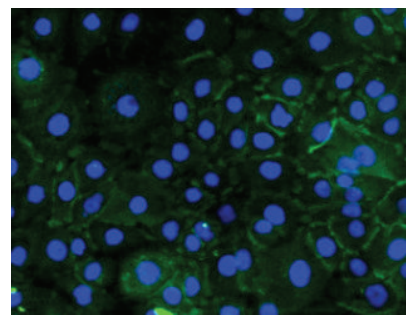

(a1)

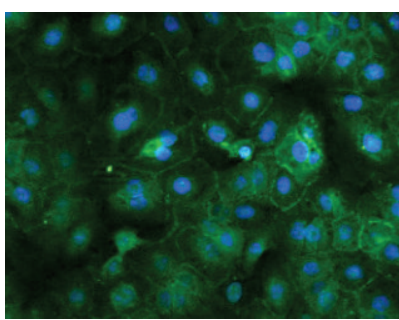

(b)

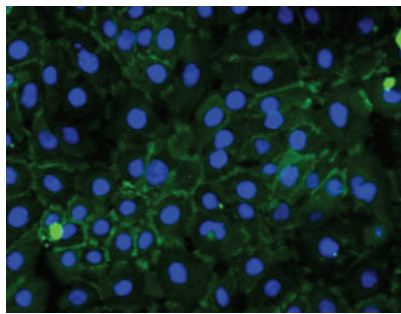

(b1)

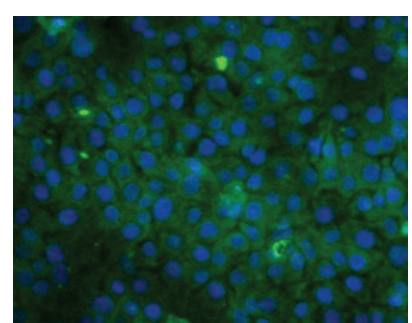

(c)

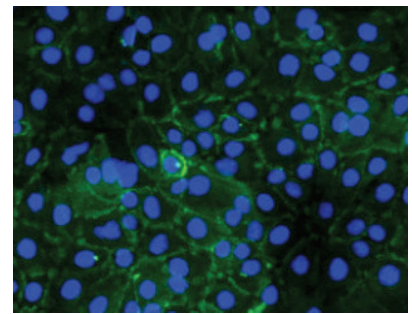

(c1)

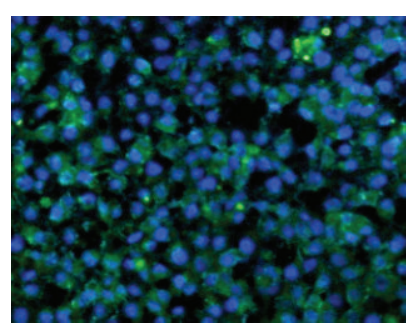

(d)

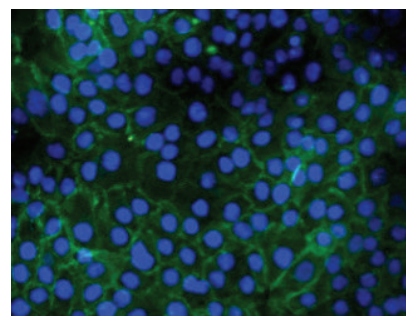

$(\mathrm{d} 1)$

FIGURE 6: Fluorescence microscopic (Apotome) images (20x) showing expression of E-cadherin in control and experimental groups of HaCaT (a-d) and HeLa (al-d1) after 5 hrs of IO treatment.

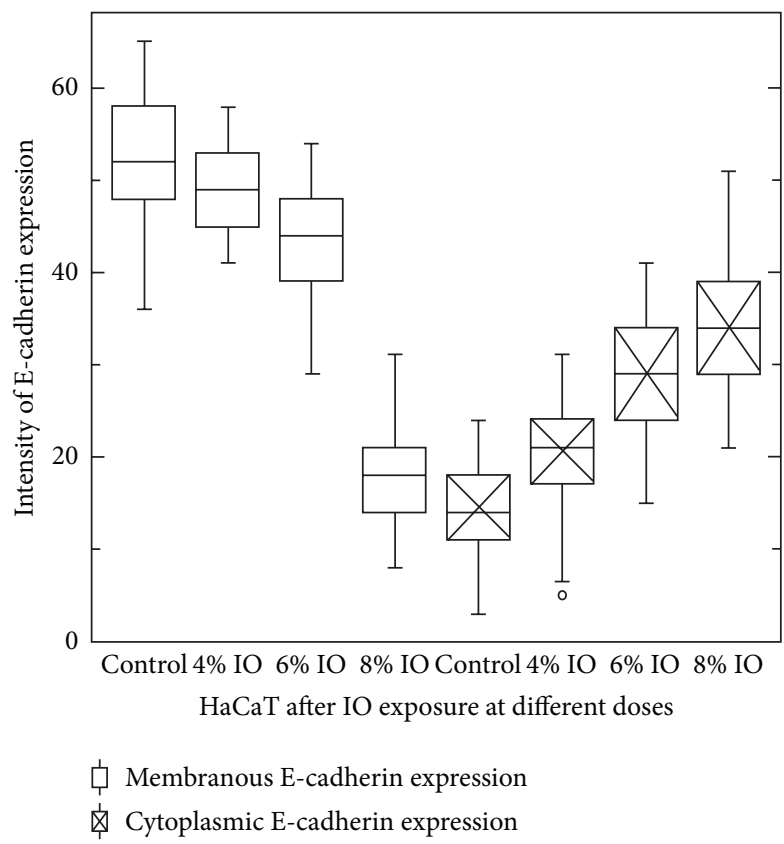

(a)

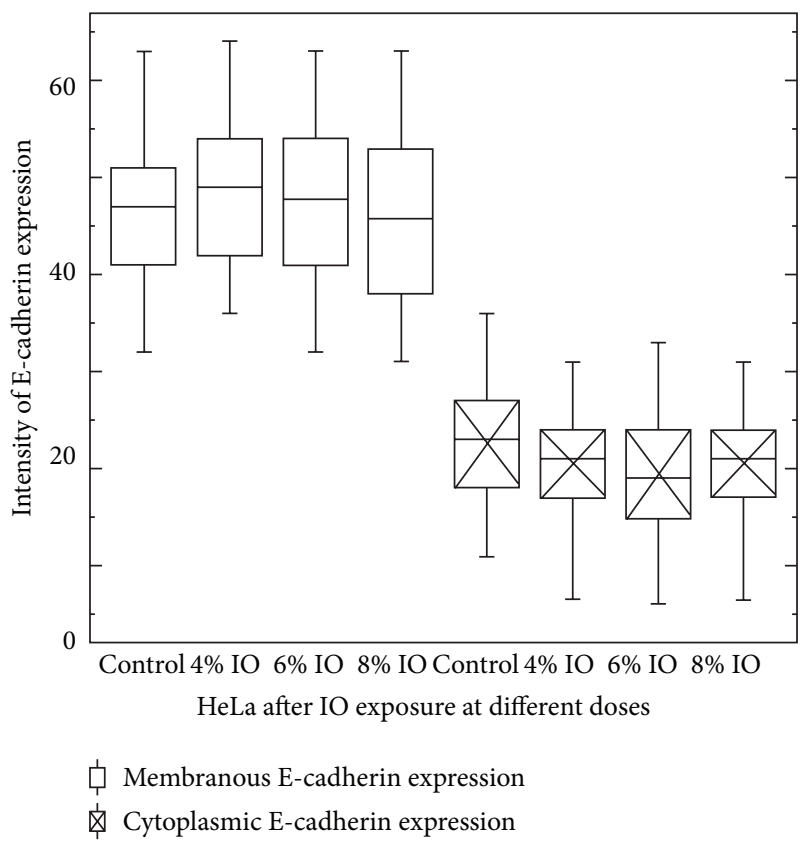

(b)

FIGURE 7: (a) Box plot depicting membranous and cytoplasmic E-cadherin intensity of HaCaT under IO exposure. (b) Box plot depicting membranous and cytoplasmic E-cadherin intensity of HeLa under IO exposure.

initial impedance value was nearly $0.2 \mathrm{M} \Omega$ at $100 \mathrm{~Hz}$ and that increased up to $0.7 \mathrm{M} \Omega$ at $800 \mathrm{~Hz}$. Thereafter, it had a steady decrease to a value nearly $1 \mathrm{~K} \Omega$ at $1 \mathrm{MHz}$ frequency. However, $8 \%$ IO treated $\mathrm{HaCaT}$ cells showed initial impedance of $0.4 \mathrm{M} \Omega$ at $100 \mathrm{~Hz}$ and then it decreased to $1 \mathrm{~K} \Omega$ at $1 \mathrm{MHz}$ without showing any peak as observed for other samples in Figure 8(a). The impedance magnitude for $8 \%$ IO treated sample had nearly one order less value than control and $4 \%$ treated samples up to $1 \mathrm{KHz}$ frequency. With increasing frequency, phase angle value did not show any significant change at lower frequency, followed by its gradual increase up to $100 \mathrm{KHz}$ and then decreased for $8 \%$ and 6\% IO incubated cells. In control and $4 \% \mathrm{IO}$ treated $\mathrm{HaCaT}$ cells, the phase angle was nearly constant for entire frequency range.

In case of HeLa (Figure 8(b)), nature of variation in impedance and phase angle was almost similar to $\mathrm{HaCaT}$ (Figure 8(a)). Although initial impedance value was almost the same, its magnitude at a particular frequency was the 


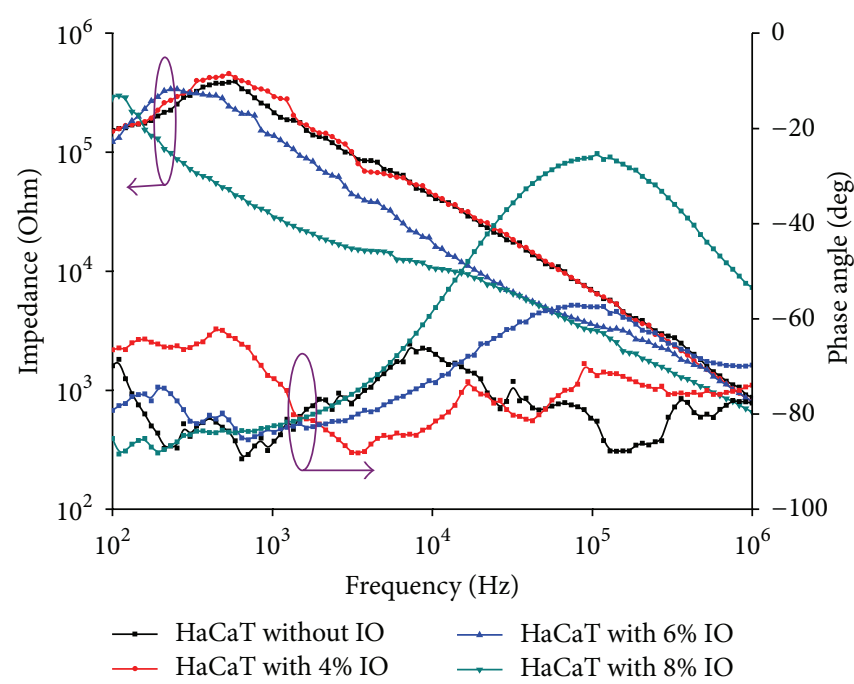

(a)

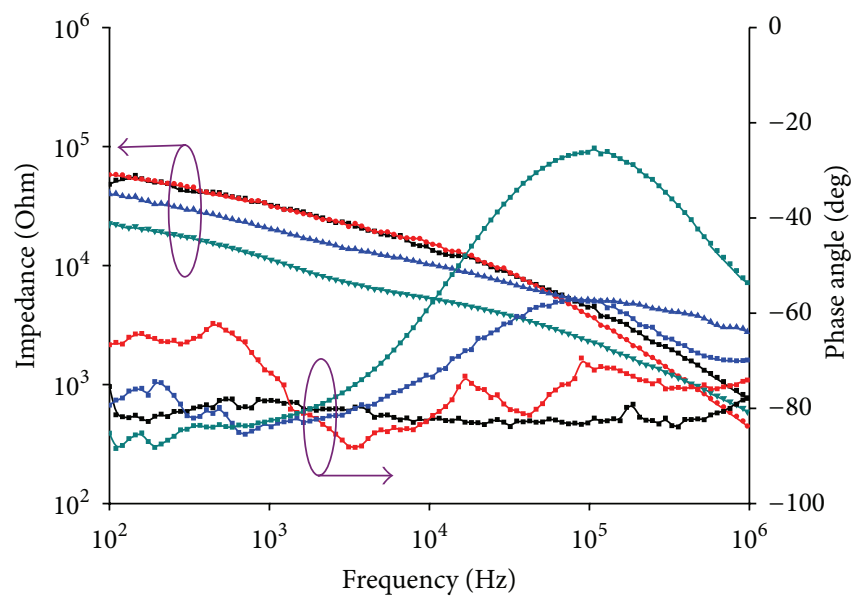

$\begin{array}{ll}\longrightarrow \mathrm{HaCaT} \text { without } \mathrm{IO} & \longrightarrow \mathrm{HaCaT} \text { with } 6 \% \mathrm{IO} \\ \longrightarrow \mathrm{HaCaT} \text { with } 4 \% \mathrm{IO} & \rightarrow \mathrm{HaCaT} \text { with } 8 \% \mathrm{IO}\end{array}$

(c)

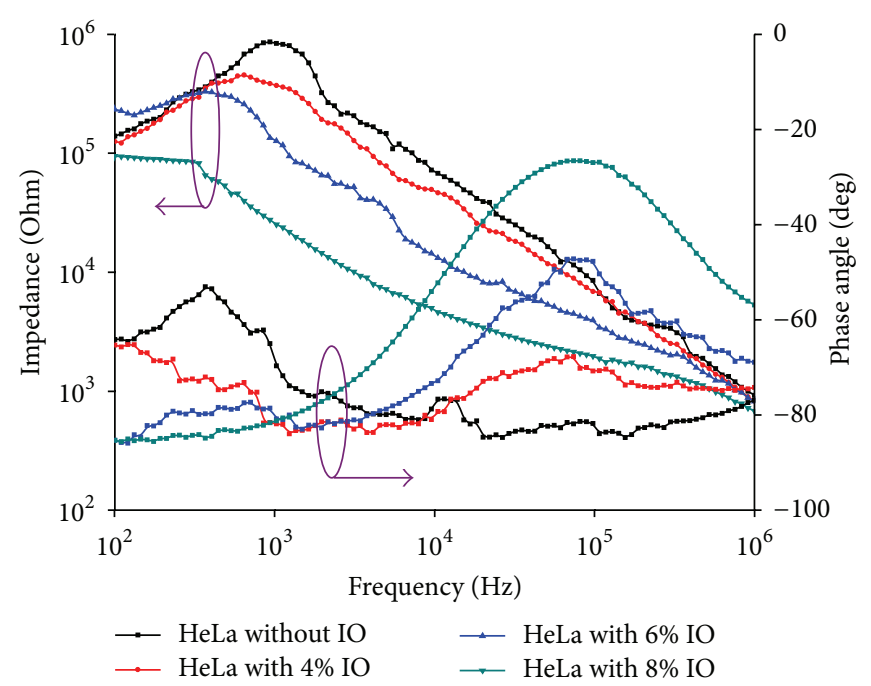

(b)

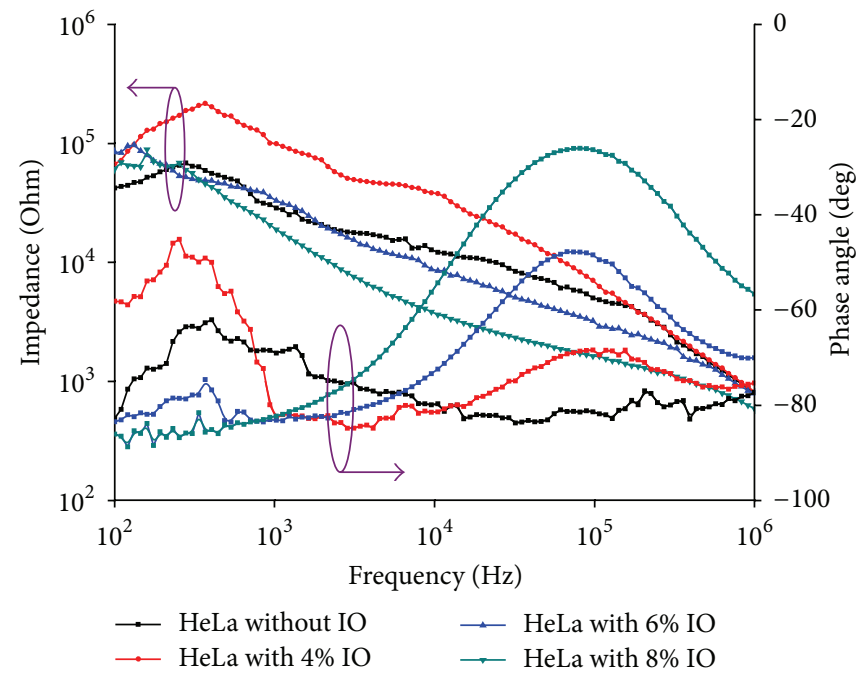

(d)

Figure 8: Semilogarithmic plot of electrical impedance $(Z)$ and phase angle $(\theta)$ against frequency $(f)$ of $\mathrm{HaCaT}($ Figures $8(\mathrm{a})-8(\mathrm{c}))$ and $\mathrm{HeLa}$ (Figures $8(\mathrm{~b})-8(\mathrm{~d}))$ at initial and final state of the experiment on exposure to different doses of IO $(0 \%, 4 \%, 6 \%$, and $8 \%$ ).

highest for control and then decreased with the higher doses of IO. Moreover, the nature of variation of impedance value was nearly linear from $1 \mathrm{KHz}$ to $1 \mathrm{MHz}$ frequency range in both the cells.

After $5 \mathrm{hrs}$ of IO treatment, the frequency response of impedance variation for $\mathrm{HaCaT}$ was entirely different from its initial measurement (Figure 8(c)) and also from 5 hrs treated HeLa cell characteristics (Figure 8(d)). The variation was linear without showing any peak and the rate of decrease was more after $0.1 \mathrm{MHz}$. However, phase angle variation was similar to that of initial state (Figure 8(a)). Thus, initial results obtained (Figures 8(a) and 8(c)) from impedance measurement might be attributed to cell death by IO treatment. On the contrary, the impedance measurement results obtained for HeLa cells (Figure 8(d)) after 5 hrs of IO treatment showed similar characteristics as obtained in its initial phase, that is, just after IO exposure (Figure 8(b)) which depicted no remarkable alteration.

\section{Discussion}

Hazard evaluation of OS is important from the perspective of its health implications [2] especially cytotoxicity [3]. The toxicity of any OS depends on the cell type and its physiological state [9]. The primary site of cytotoxic action is cytoplasmic membrane of cells [3]. Cytotoxicity of IO on microorganism like yeast has already been reported [10] but its impact on the mammalian cells is not well documented. Only the positive effect of IO in combination with acetic acid in psoriasis is reported [11]. Under these circumstances, present study on effects of IO on epithelial cells, that is, keratinocytes, which 
are involved in diverse protective functions in epithelium $[12,13]$, exposed to frequent physical and chemical assaults compared to any other tissues [14] and connected with $90 \%$ cancers development [15] is considered to be important.

Evaluation of cytotoxicity through multimodal analysis is effective to have a correlated understanding of cellular changes under assaults. This study has evaluated the differential effects of IO exposures on HaCaT and HeLa when incubated for $5 \mathrm{hrs}$ after intervention. Interestingly it unveiled a disparity in IO effects on normal and cancerous cell lines in respect to their structural and functional integrity. The correlated assessment of changes in the cellular viability, ultrastructure, and molecular expressions including bioelectrical properties provided important information on effects of IO on $\mathrm{HaCaT}$ and HeLa.

The cell viability assay rendered useful information about the differential response of $\mathrm{HaCaT}$ and HeLa under same IO doses. Percentages of cell viability under different doses of this OS have directly depicted the degree of toxicity on the cell types (Figure 3). Further, live-dead cell assay was supportive to demonstrate differential impact of IO on HaCaT and HeLa (Figure 2). Under chemical assaults, the cells usually become stressed; resulting in alteration in cellular functioning. This in turn may bring changes in morphology as well as in cell-cell association [19]. Here, ultrastuctural microphotographs and ICC observations clearly depicted the impairment in cell-cell association in confluent population along with disruption in membranous E-cadherin of $\mathrm{HaCaT}$ under IO exposures especially at higher doses in contrast to HeLa where no alterations were noted (Figure 4).

The present study evidently pointed out the correlation between changes in cellular morphology and cellular adherent junction related prime molecule (i.e., E-cadherin) for cell-cell association in $\mathrm{HaCaT}$ under $\mathrm{IO}$ exposure. In fact reduction in membranous E-cadherin expression is an indicator of disruption in epithelial integrity [21]. Studies have shown that the loss of E-cadherin is associated with the development of cancer in humans. Moreover, the loss of cellcell interaction due to depletion in E-cadherin results in acquiring the migratory features in the cells thus contributing to the increase in malignant potentiality $[20-22,45]$. However, it was interesting to note that though E-cadherin expression was affected in HaCaT under IO exposure, as a whole, its transcriptomic expression remained higher than HeLa (Figure 5) which was just reverse to the protein expression (Figure 6). The impairment in cellular association of $\mathrm{HaCaT}$ was manifested at the molecular level as demonstrated by transcriptomic downregulation of E-cadherin and its dislocation from membranous sites as observed in Figures 5, 6, and 7. But no remarkable alteration was noted for HeLa under IO treatment. The above study could be compared with the published literature $[21,46]$ which signified that the disruption in epithelial cell-cell association could be due to reduction in membranous E-cadherin expression. The decrease in cell viability is also related to the loss of Ecadherin as evident from the published literature [46] and corroborative with the present study. It has already been reported that the loss of E-cadherin in early mouse embryos and lactating mammary glands results in tissue dysfunction and cell death $[45,46]$.

The bioelectrical properties of cells and their alterations under assaults [22] are important in evaluating cytotoxicity [24]. In different functional conditions as well as in adhered conditions, cells exhibit changes in electrical properties like membrane potential, impedance, charge distribution, and so forth $[27,32]$. In this study, under IO exposure, the membrane permeability of $\mathrm{HaCaT}$ was possibly affected as indicated by disruption of membranous E-cadherin along with its increased appearance in cytoplasmic sites (Figure 7) and this change in membrane integrity was also reflected in the electrical bioimpedance variation of these cells. The unaffected HeLa depicted no alteration in the impedance (Figure 8) as noted at the initial and late state (after $5 \mathrm{hrs)} \mathrm{of}$ IO exposure. As the cell membrane of HeLa might be porous and even without membranous E-cadherin disruption, there was a steep fall in the impedance for entire frequency range. But not much change was noted in the impedance pattern. A major randomness, which was observed in the variation of phase angle of $\mathrm{HeLa}$, indicated its differential response to IO and its resistance to these chemical stresses.

There is an increase of impedance value up to frequency around $100 \mathrm{~Hz}$ and thereafter its value decreases steadily at higher frequency as observed for both the cell lines at their initial phase (Figures 8(a) and 8(b)). At the final stage after IO exposure, the impedance value gradually decreases with frequency for its entire frequency range as observed in Figure 8(c) for HaCaT. Comparing the results obtained in Figures $8(\mathrm{a})$ and $8(\mathrm{c})$ it is clearly observed that characteristics of bioimpedance for $\mathrm{HaCaT}$ are modified greatly which is attributed to IO effects. However, for HeLa there are no major observable changes in Figures 8(b) and 8(d) due to its comparatively chemotoxic resistant property. The distinct difference between $\mathrm{HaCaT}$ and HeLa in respect to impedance characteristics under IO exposure thus illustrated differential toxic impact on the two cell lines and these were corroborative with the observed structural and functional changes. Indeed the remarkable toxic effects of IO on $\mathrm{HaCaT}$ and evasion of toxicity by HeLa may be the indication that this OS affects normal epithelial cells but not the comparatively chemotoxicity resistant cancer cells. Initial bioimpedance results presented in this study indicate qualitatively that monitoring electrical properties of cells is also important in evaluating cytotoxic effect in different cell lines. In future study the change in $R$ and other electrical parameters of cells may be estimated further for quantitative assessment of cytotoxic effects.

\section{Conclusion}

The cytotoxic effects of IO doses on HaCaT and HeLa were explored by multimodal analysis of the cellular features. Remarkable changes were observed in $\mathrm{HaCaT}$ but not in $\mathrm{HeLa}$, in respect to morphology, viability, cellular association, E-cadherin expression, and electrical impedance particularly on exposure to higher doses. The distinct difference in electrical bioimpedance variation between the affected ( $\mathrm{HaCaT})$ 
and unaffected (HeLa) cells in association with other cytological features under the chemical assault was effective not only in demonstrating IO's cytotoxicity on normal epithelial cells from multiple dimensions but also in indicating potentiality of bioelectrical parameters (impedance) to come out as a level free marker for cytotoxicological assessment.

\section{Conflict of Interests}

The authors declare that there is no conflict of interests regarding the publication of this paper.

\section{Acknowledgments}

Financial support through the National Program on Micro and Smart Systems (NPMASS), Government of India, for this study, is greatly acknowledged.

\section{References}

[1] Official Journal of theEuropean Union, vol. 396, pp. 1-849, 2006.

[2] P. J. Bushnell, W. K. Boyes, T. J. Shafer, A. S. Bale, and V. A. Benignus, "Approaches to extrapolating animal toxicity data on organic solvents to public health," NeuroToxicology, vol. 28, no. 2, pp. 221-226, 2007.

[3] C. Tanford, The Hydrophobic Effect: Formation of Micelles and Biological Membranes, John Wiley \& Sons, New York, NY, USA, 2nd edition, 1980.

[4] C. Tanford, "Protein denaturation. Theoretical models for the mechanism of denaturation," Advances in Protein Chemistry, vol. 24, pp. 1-95, 1970.

[5] http://toxnet.nlm.nih.gov/.

[6] D. Werner, R. Arno, S. Andrea, and R. Klaus, "Automotive fuels," in Ullmann's Encyclopedia of Industrial Chemistry, Wiley-VCH, Weinheim, Germany, 2007.

[7] G. E. Totten, S. R. Westbrook, and R. J. Shah, Fuels and Lubricants Handbook, ASTM International, West Conshocken, $\mathrm{Pa}$, USA, 2003.

[8] U.S. Environmental Protection Agency, Toxicological Review for 2,2,4-Trimethylpentane, Oak Ridge Institute for Science and Education, Oak Ridge Associated Universities, 2007.

[9] J. A. Schellman, "Solvent denaturation," Biopolymers, vol. 17, no. 5, pp. 1305-1322, 1978.

[10] S. Miura, W. Zou, M. Ueda, and A. Tanaka, "Screening of genes involved in isooctane tolerance in Saccharomyces cerevisiae by using mRNA differential display," Applied and Environmental Microbiology, vol. 66, no. 11, pp. 4883-4889, 2000.

[11] B. Johansen, M. Anthonsen, W. Sjursen, A. K. Holmeide, and L. Skattebol, "Use of polyunsaturated ketones for the treatment of psoriasis," US Patent, 2010.

[12] A. J. Ross, L. A. Dailey, L. E. Brighton, and R. B. Devlin, "Transcriptional profiling of mucociliary differentiation in human airway epithelial cells," American Journal of Respiratory Cell and Molecular Biology, vol. 37, no. 2, pp. 169-185, 2007.

[13] M. Jarnik, M. N. Simon, and A. C. Steven, "Cornified cell envelope assembly: a model based on electron microscopic determinations of thickness and projected density," Journal of Cell Science, vol. 111, no. 8, pp. 1051-1060, 1998.
[14] H. M. Frederic, F. B. Edwin, C. O. William, W. G. Claire, W. Kathleen, and T. H. Ralph, Essentials of Anatomy \& Physiology, Pearson/Benjamin Cummings, London, UK, 4th edition, 2007.

[15] J. E. Visvader, “Cells of origin in cancer," Nature, vol. 469, no. 7330, pp. 314-322, 2011.

[16] A. Cannavò, P. Ceci, D. Coletti et al., "Toxic effects of polychlorinated biphenyls in myogenic cells," Journal of Health Science, vol. 50, no. 1, pp. 33-41, 2004.

[17] A. M. Schrand, M. F. Rahman, S. M. Hussain, J. J. Schlager, D. A. Smith, and A. F. Syed, "Metal-based nanoparticles and their toxicity assessment," Wiley Interdisciplinary Reviews: Nanomedicine and Nanobiotechnology, vol. 2, no. 5, pp. 544-568, 2010.

[18] L. Wang, D. K. Nagesha, S. Selvarasah, M. R. Dokmeci, and R. L. Carrier, "Toxicity of CdSe nanoparticles in Caco-2 cell cultures," Journal of Nanobiotechnology, vol. 6, article 11, 2008.

[19] I. Pujalté, I. Passagne, B. Brouillaud et al., "Cytotoxicity and oxidative stress induced by different metallic nanoparticles on human kidney cells," Particle and Fibre Toxicology, vol. 8, article 10, 2011.

[20] T. Jakob, M. J. Brown, and M. C. Udey, "Characterization of Ecadherin-containing junctions involving skin-derived dendritic cells," Journal of Investigative Dermatology, vol. 112, no. 1, pp. 102-108, 1999.

[21] S. Yamada, S. Pokutta, F. Drees, W. I. Weis, and W. J. Nelson, "Deconstructing the cadherin-catenin-actin complex," Cell, vol. 123, no. 5, pp. 889-901, 2005.

[22] I. H. Heijink, P. M. Kies, H. F. Kauffman, D. S. Postma, A. J. M. Van Oosterhout, and E. Vellenga, "Down-regulation of Ecadherin in human bronchial epithelial cells leads to epidermal growth factor receptor-dependent Th2 cell-promoting activity," Journal of Immunology, vol. 178, no. 12, pp. 7678-7685, 2007.

[23] R. A. Charman, "Part 3: bioelectric potentials and tissue currents," Physiotherapy, vol. 76, no. 10, pp. 643-654, 1990.

[24] R. A. Charman, "Introduction part I: the electric cell," Physiotherapy, vol. 76, pp. 502-508, 1990.

[25] W. C. Prozialeck and P. C. Lamar, "Cadmium $\left(\mathrm{Cd}^{2+}\right)$ disrupts Ecadherin-dependent cell-cell junctions in MDCK cells," In Vitro Cellular \& Developmental Biology-Animal, vol. 33, no. 7, pp. 516-526, 1997.

[26] F. Asphahani and M. Zhang, "Cellular impedance biosensors for drug screening and toxin detection," Analyst, vol. 132, no. 9, pp. 835-841, 2007.

[27] J. J. Killion, "Electrical properties of normal and transformed mammalian cells," Biophysical Journal, vol. 45, no. 3, pp. 523$528,1984$.

[28] C. L. Davey, G. H. Markx, and D. B. Kell, "On the dielectric method of monitoring cellular viability," Pure and Applied Chemistry, vol. 65, pp. 1921-1926, 1993.

[29] N. Bao, J. Wang, and C. Lu, "Recent advances in electric analysis of cells in microfluidic systems," Analytical and Bioanalytical Chemistry, vol. 391, no. 3, pp. 933-942, 2008.

[30] M. Brouard, M. Casado, S. Djelidi, Y. Barrandon, and N. Farman, "Epithelial sodium channel in human epidermal keratinocytes: expression of its subunits and relation to sodium transport and differentiation," Journal of Cell Science, vol. 112, no. 19, pp. 3343-3352, 1999.

[31] P. K. Chakraborty, W.-K. Lee, M. Molitor, N. A. Wolff, and F. Thévenod, "Cadmium induces Wnt signaling to upregulate proliferation and survival genes in sub-confluent kidney proximal tubule cells," Molecular Cancer, vol. 9, article 102, 2010. 
[32] F. Asphahani, M. Thein, O. Veiseh et al., "Influence of cell adhesion and spreading on impedance characteristics of cell-based sensors," Biosensors and Bioelectronics, vol. 23, no. 8, pp. 13071313, 2008.

[33] S. Arndt, J. Seebach, K. Psathaki, H.-J. Galla, and J. Wegener, "Bioelectrical impedance assay to monitor changes in cell shape during apoptosis," Biosensors and Bioelectronics, vol. 19, no. 6, pp. 583-594, 2004.

[34] G. T. A. Kovacs, "Electronic sensors with living cellular components," Proceedings of the IEEE, vol. 91, no. 6, pp. 915-929, 2003.

[35] L. Ceriotti, J. Ponti, F. Broggi et al., "Real-time assessment of cytotoxicity by impedance measurement on a 96-well plate," Sensors and Actuators B, vol. 123, no. 2, pp. 769-778, 2007.

[36] C. Xiao and J. H. T. Luong, "On-line monitoring of cell growth and cytotoxicity using electric cell-substrate impedance sensing (ECIS)," Biotechnology Progress, vol. 19, no. 3, pp. 1000-1005, 2003.

[37] K. H. Gilchrist, L. Giovangrandi, R. H. Whittington, and G. T. A. Kovacs, "Sensitivity of cell-based biosensors to environmental variables," Biosensors and Bioelectronics, vol. 20, no. 7, pp. 13971406, 2005.

[38] C. Hartmann, A. Zozulya, J. Wegener, and H.-J. Galla, "The impact of glia-derived extracellular matrices on the barrier function of cerebral endothelial cells: an in vitro study," Experimental Cell Research, vol. 313, no. 7, pp. 1318-1325, 2007.

[39] H. Yin, F. L. Wang, A. L. Wang, J. Cheng, and Y. Zhou, "Bioelectrical impedance assay to monitor changes in aspirintreated human colon cancer HT-29 cell shape during apoptosis," Analytical Letters, vol. 40, no. 1, pp. 85-94, 2007.

[40] H. Morgan, T. Sun, D. Holmes, S. Gawad, and N. G. Green, "Single cell dielectric spectroscopy," Journal of Physics D: Applied Physics, vol. 40, no. 1, article S10, pp. 61-70, 2007.

[41] R. M. Lee, H. Choi, J.-S. Shin, K. Kim, and K.-H. Yoo, "Distinguishing between apoptosis and necrosis using a capacitance sensor," Biosensors and Bioelectronics, vol. 24, no. 8, pp. 25862591, 2009.

[42] M. C. Phelan, Current Protocols in Cell Biology, John Wiley \& Sons, 1998.

[43] B. Ekwall, V. Silano, A. Paganuzzi-Stammati, and F. Zucco, Toxicity Tests with Mammalian Cell Cultures, chapter 7, 1990.

[44] D. Fraga, T. Meulia, and S. Fenster, Real-Time PCR; Current Protocols Essential Laboratory Techniques 10.3.1-10.3.33, John Wiley \& Sons, 2008.

[45] M. Ohsugi, L. Larue, H. Schwarz, and R. Kemler, "Cell-functional and cytoskeletal organization in mouse blastocysts lacking E-cadherin," Developmental Biology, vol. 185, no. 2, pp. 261271, 1997.

[46] C. L. Tinkle, T. Lechler, H. A. Pasolli, and E. Fuchs, "Conditional targeting of E-cadherin in skin: insights into hyperproliferative and degenerative responses," Proceedings of the National Academy of Sciences of the United States of America, vol. 101, no. 2, pp. 552-557, 2004. 

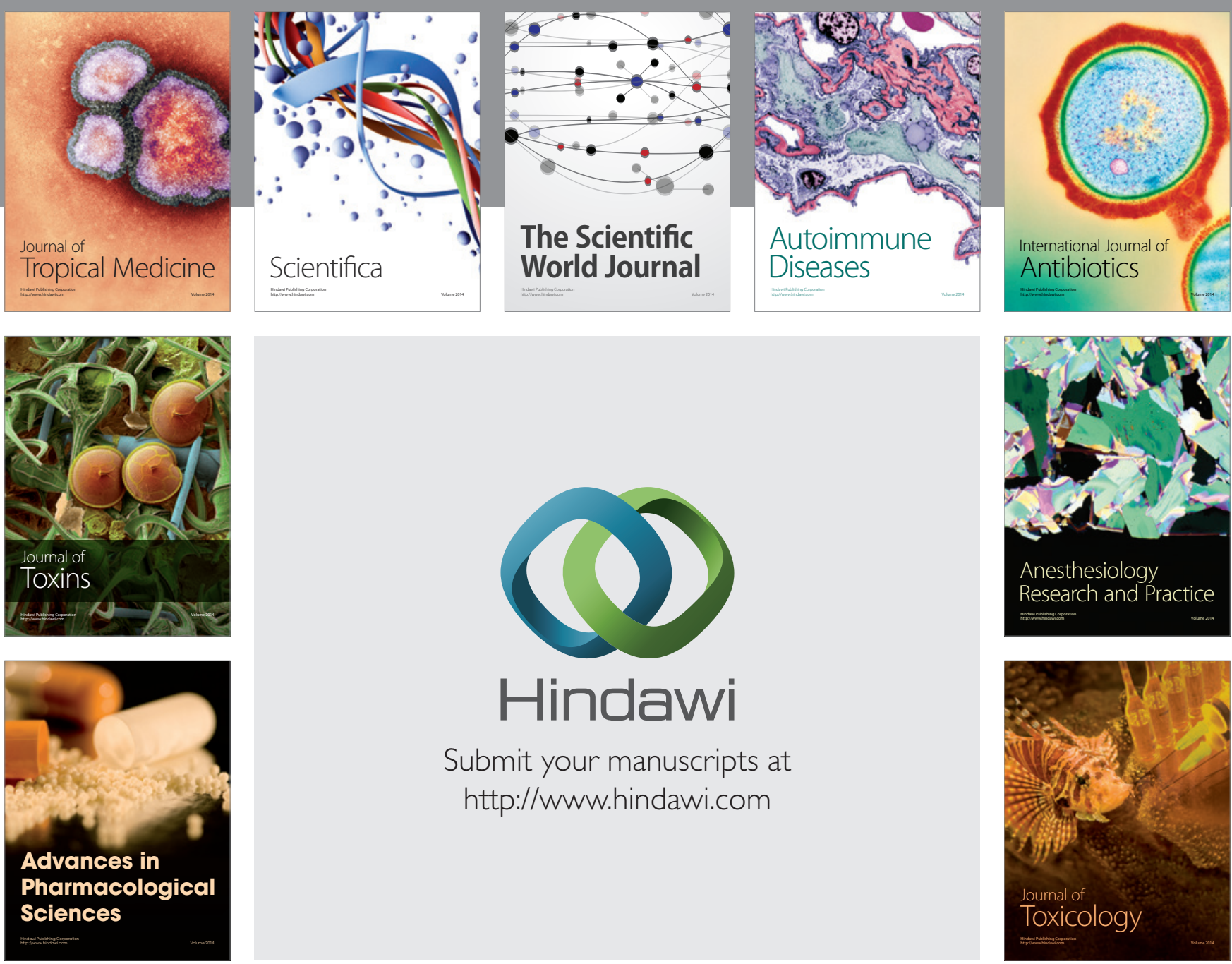

\section{Hindawi}

Submit your manuscripts at

http://www.hindawi.com
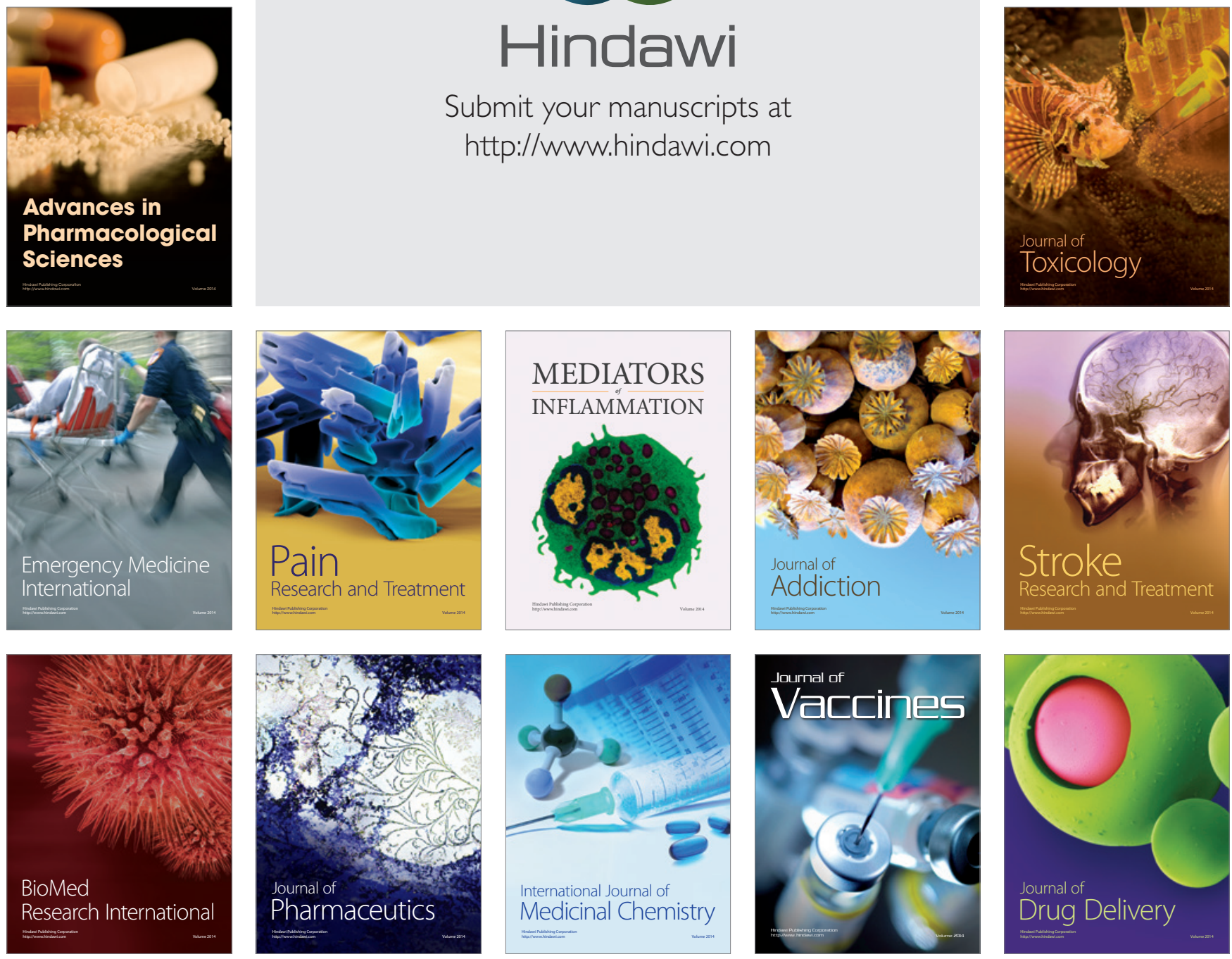